\title{
Получение и исследование адсорбентов на основе ультрадисперсного диоксида кремния и $\beta$-циклодекстрина
}

\author{
(C) 2019 Копытина Н.А., Копытин К.А., Парийчук М.Ю. \\ Самарский национальный исследовательский университет имени академика С.П. Королева, Самара
}

Поступила в редакцию 23.09.2019 г.

DOI: 10.17308/sorpchrom.2019.19/2224

Получены поверхностно-слойные адсорбенты путем нанесения наночастиц диоксида кремния и наночастиц диоксида кремния, модифицированных незамещенным $\beta$-циклодекстрином, на инертный кремнеземный носитель. Определены геометрические параметры полученных адсорбентов. Методом газо-адсорбционной хроматографии изучены адсорбционные свойства полученных образцов по отношению к парам органических соединений различной природы, в том числе энантиомерам, и рассчитаны термодинамические характеристики адсорбции для исследованных соединений. Предложен вариант строения наночастиц, модифицированных циклодекстрином.

Ключевые слова: адсорбция, структурная организация, наноструктуры, молекулярное распознавание, комплексообразование «гость - хозяин», хиральность, селективность, поверхностнослойные адсорбенты

\section{Preparation and study of adsorbents based on silica nanoparticles and $\beta$-cyclodextrin}

\author{
(C) 2019 Kopytina N.A., Kopytin K.A., Pariychuk M.Yu. \\ Samara University, Samara
}

\begin{abstract}
The work is devoted to the preparation and study of new functional materials with a chiral structure for sorption and chromatographic technologies used for the separation and concentration of organic compounds, including isomers of various types and optically active compounds. To obtain a composite adsorbent, silicon dioxide nanoparticles (butasil) were modified with unsubstituted $\beta$-cyclodextrin, and then they were applied on a silica support Chromaton N-AW. Also an adsorbent with silicon dioxide nanoparticles without cyclodextrin was also obtained. Using low-temperature nitrogen adsorption, the geometric characteristics of both adsorbents were determined. The study of the adsorption properties of adsorbents with respect to pairs of organic compounds of various nature was carried out by gas chromatography. From the obtained temperature dependences of the Henry adsorption constants, the thermodynamic characteristics of adsorption for the studied compounds were calculated. It was found that for both studied adsorbents, the values of specific surface areas are close and significantly differ from the corresponding values for butasil $\left(176.4 \mathrm{~m}^{2} / \mathrm{g}\right)$ and solid support (2-4 $\left.\mathrm{m}^{2} / \mathrm{g}\right)$. The modification of butasil nanoparticles with $\beta$-cyclodextrin seems to lead to a slight increase in the specific surface area and pore volume of the Bsil/CD adsorbent compared to the Bsil adsorbent due to intramolecular cavities. Based on the values of the thermodynamic characteristics of adsorption, it was concluded that, in the case of the Bsil/CD adsorbent, for the molecules of the studied adsorbates, a guest - host complexation is detected. In this case, for cyclic and bicyclic structures, difficulty is observed with inclusion in the cavity. Further, for alkanols, both outer-sphere and intra-sphere complexation is possible. A possible structure of silicon dioxide nanoparticles modified with unsubstituted $\beta$-cyclodextrin was proposed based on the obtained data. In the proposed structure, butyl fragments on the particle surface play
\end{abstract}


the role of «guests» and are included in the macrocyclic cavities of cyclodextrin molecules. Thus, butyl fragments on the particle surface act as anchor groups orienting macrocyclic molecules. The resulting orientation of cyclodextrin molecules is favorable for the formation of complexes of different stability with enantiomeric molecules, which is showed in high enantioselectivity for terpenes (limonene, camphene, pinene).

Keywords: adsorption, structural organization, nanostructures, molecular recognition, host - guest complexation, chirality, selectivity, surface-layer adsorbents

\section{Введение}

Исследование нано- или ультра- дисперсного состояния вещества, а также разработка подходов получения наноструктурированных материалов и исследование возможностей их практического применения являются важными задачами физической, коллоидной химии и современного материаловедения. Получение наночастиц различной химической природы позволяет конструировать на их основе композитные материалы с особыми механическими [1,2], оптическими [3], теплофизическими [1], сенсорными [4], сорбционными [5,6], каталитическими [7] и другими свойствами. Функционализация поверхности наночастиц имеет место при их получении, а также используется для целенаправленного придания им требуемых свойств. В частности, в литературе описаны подходы функционализации наночастиц металлов [8] или наночастиц диоксида кремния [9] с помощью циклодекстринов. Интерес к таким модифицированным наночастицам обусловлен способностью молекул циклодекстрина к образованию комплексов включения с различными субстратами в объемных фазах. При этом их адсорбционные свойства на границе раздела фаз «газ - твердое тело» не исследовались.

Таким образом, целью настоящей работы было получение и исследование адсорбционных энантиоселективных свойств композитов на основе наночастиц диоксида кремния и наночастиц диоксида кремния, модифицированных незамещенным $\beta$-циклодекстрином, по отношению к парам органических соединений в условиях газо-адсорбционной хроматографии.

\section{Эксперимент}

Приготовление адсорбентов. В качестве наночастиц диоксида кремния, модифицируемых циклодекстрином, выбран аэросил, поверхность которого гидрофобизирована за счет пришивки бутильных групп (бутасил). По данным атомносиловой микроскопии размер частиц бутасила составил от 5 нм до 60 нм. Выбор основан на предположении, что при модифицировании наночастиц диоксида кремния циклодекстринами будет реализовываться включение бутильных фрагментов в макроциклические полости, тем самым обеспечивая их лучшую ориентацию для взаимодействия с молекулами «гостей». При этом, поскольку на поверхности ультрадисперсного бутасила частично остаются свободные силанольные группы, возможно также образование водородных связей с гидроксильными группами циклодекстрина. Указанные факторы позволяет физически закрепить молекулы циклодекстрина на наночастицах. Для модифицирования наночастиц бутасила использовался незамещенный $\beta$-циклодекстрин (CD), Sigma-Aldrich, поскольку он обладает наиболее открытой и доступной полостью по сравнению с замещенными циклодекстринами. Носителем для модифицированных наночастиц являлся силанизированный носитель Хроматон N-AW. Приготовление композиционных адсорбентов проходило следующим образом. Для получения адсорбента на основе исходного бутасила (Bsil) готовили суспензию наночастиц в хлористом метилене, которую обрабатывали с помощью ультразвука для механического диспергирования агрегированных частиц. По- 
сле этого в нее вносили твердый носитель (Хроматон), а потом органическую среду удаляли отгонкой под вакуумом. Для приготовления адсорбента (Bsil/CD), содержащего циклодекстрин, последний предварительно растворяли в водном растворе метанола, в полученный раствор добавляли навеску бутасила, после чего смесь обрабатывали с помощью ультразвука. Затем суспензию оставляли на трое суток. Растворитель отгоняли на ротационном испарителе. После этого готовили суспензию модифицированных наночастиц в хлористом метилене, в которую добавляли Хроматон. Как и в предыдущем случае органическую среду удаляли на ротационном испарителе. Полученными композиционными адсорбентами заполняли стеклянные колонки, которые кондиционировали при температуре $240{ }^{\circ} \mathrm{C}$ в токе азота.

Для определения текстурных характеристик адсорбентов использовали метод низкотемпературной адсорбции/десорбции азота, реализованный на анализаторе удельной поверхности Autosorb-1 (Quantochrome). Для расчета удельной площади поверхности использовали модель Брунауэра-Эммета-Тэллера (БЭТ). Общий объем пор и распределение пор по размерам рассчитывали по десорбционной кривой с использованием модели Баррета-Джойнера-Халенды (ВJH).

В качестве адсорбатов был выбран набор веществ, чьи молекулы имеют различное строение и природу и способны участвовать в различных межмолекулярных взаимодействиях. В список использованных соединений также входили энантиомерные соединения.

Расчет термодинамических характеристик адсорбции. Термодинамические характеристики адсорбции органических соединений из газовой фазы на полученных адсорбентах определяли с помощью метода газо-адсорбционной хроматографии. Эксперимент проводили на хроматографе «Кристалл 5000.2» с пламенноионизационным детектором.

На основании экспериментальных данных рассчитывали константу Генри адсорбции по формуле:

$$
K_{1, c}=V_{S}^{T}=\frac{\left(t_{R}-t_{M}\right) \cdot F_{P_{a}, T_{c}} \cdot j_{3}^{2}}{W_{S} \cdot s_{y d}}=\frac{\left(t_{R}-t_{M}\right) \cdot F_{\bar{P}, T_{c}}}{W_{S} \cdot s_{y \partial}}
$$

где $t_{R}$ - время удерживания исследуемого вещества; $t_{M}$ - время удерживания несорбирующегося вещества; $W_{s}$ - масса адсорбента; $s_{y d}$ - удельная поверхность адсорбента; $F_{P_{a}, T_{c}}$ - объемная скорость газа-носителя на выходе из колонки при температуре колонки; $j_{3}^{2}-$ коэффициент Джеймса - Мартина; $F_{\bar{P}, T_{c}}$ - объемная скорость газа-носителя, приведенная к температуре колонки и усредненному по длине колонки давлению, для определения которой использовали метод «холодной» градуировки [10].

Из температурных зависимостей константы Генри определяли дифференциальную молярную теплоту адсорбции $\left(\bar{q}_{d i f, 1}\right)$, а также изменение энтропии при адсорбции $\left(\Delta \bar{S}_{1, c}^{0}\right)$ по известному соотношению [11]:

$$
\ln K_{1, c}=\frac{B}{T}+A=\frac{\bar{q}_{d i f, 1}}{R T}+\frac{\Delta \bar{S}_{1, c}^{0}}{R}+1
$$

где $\bar{q}_{d i f, 1}=-\Delta \overline{\mathrm{U}}_{1}-$ изменение внутренней энергии при адсорбции; $\Delta \bar{S}_{1, c}^{0}=\bar{S}_{1}^{o}-\tilde{S}_{g, c}^{o}$, $\bar{S}_{1}^{o}$ - стандартная ( $\Gamma=1$ мкмоль/м²) дифференциальная энтропия адсорбированного вещества, $\widetilde{S}_{g, C}^{o}-$ стандартной энтропии адсорбата в газовой фазе при концентрации $C=1$ мкмоль $/ \mathrm{cm}^{3}$.

Копытина и др. / Сорбционные и хроматографические процессы. 2019. Т. 19. № 6. С. 636-644 


\section{Обсуждение результатов}

Характеристики пористой структуры для готовых композиционных адсорбентов и исходного бутасила были определены с помощью низкотемпературной адсорбции/десорбции азота (таблица 1). Для исходного бутасила удельная площадь поверхности составила $176.4 \mathrm{~m}^{2} / \Gamma$.

Таблица 1. Геометрические характеристики изученных адсорбентов

\begin{tabular}{|c|c|c|c|}
\hline Название & $S_{y d}($ БЭТ $), \mathrm{m}^{2} / \Gamma$ & $V_{\text {nop }}(\mathrm{BJH} \mathrm{des}), \mathrm{cm}^{3} / \Gamma$ & $D_{э \phi}(\mathrm{BJH}$ des $)$, нм \\
\hline Bsil & 23.2 & 0.371 & 3.4 \\
\hline Bsil/CD & 24.9 & 0.387 & 3.4 \\
\hline
\end{tabular}

Из представленных в таблице 1 данных видно, что нанесение непористых наночастиц бутасила на поверхность Хроматона $\left(s_{y \partial}=2-4 \mathrm{~m}^{2} / \Gamma\right)$ во всех случаях сопровождается уменьшением общей поверхности в сравнении с исходным ультрадисперсным диоксидом кремния. Этот эффект связан с тем, что частицы бутасила заполняют макропоры Хроматона, образуя мезопоры. Стоит отметить, что для обоих изученных адсорбентов обнаружено полимодальное распределение пор по размерам в области мезопор от 4 до 20 нм, подтверждающее данные атомно-силовой микроскопии, что частицы бутасила в целом имеют широкий разброс по диаметрам. Возможно, что при приготовлении адсорбентов диспергирование ультразвуком не привело к разрушению всех агрегатов частиц диоксида кремния, и они неравномерно заполнили поры исходного твердого носителя. Также можно отметить некоторое увеличение удельной поверхности и порового объема у адсорбента Bsil/CD в сравнении с адсорбентом Bsil, по-видимому, связанное с присутствием циклодекстрина, дающего дополнительные поверхность и объем за счет внутримолекулярных полостей. На рисунке 1 представлены температурные зависимости константы Генри адсорбции для н-алканов на двух исследованных адсорбентах.

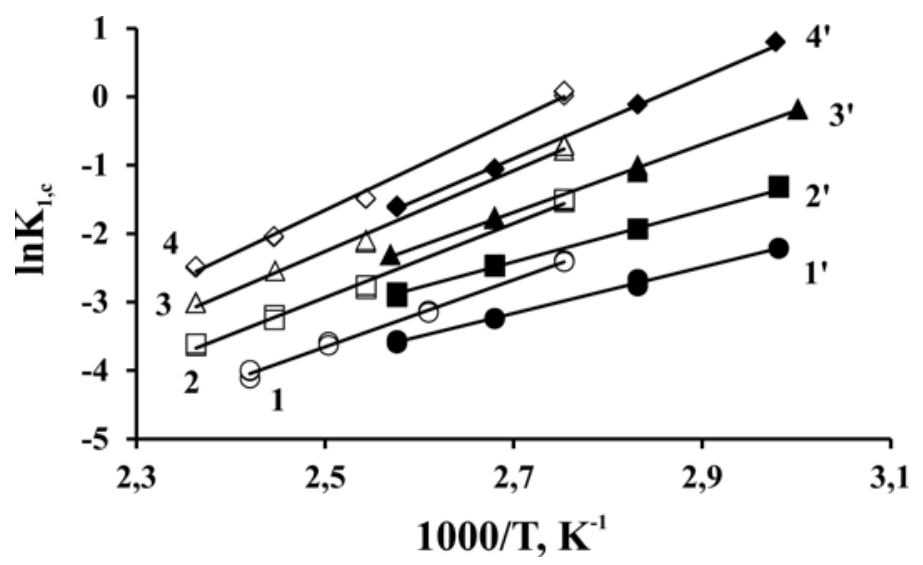

Рис. 1. Зависимости логарифма константы Генри от обратной температуры для н-гексана (1, 1'), н-гептана (2, 2'), н-октана (3, 3') и н-нонан $\left(4,4^{\prime}\right)$ на адсорбентах Bsil (1-4) и Bsil/CD (1'-4').

Из приведенного рисунка 1 видно, что модифицирование наночастиц бутасила циклодекстрином привело к снижению их адсорбционного потенциала, о чем свидетельствует уменьшение наклона температурных зависимостей н-алканов на адсорбенте Bsil/CD по сравнению с адсорбентом Bsil. Наибольшее уменьшение наклона наблюдается для н-гексана и н-гептана. В то же время с удлинением углеводородной цепи н-алкана наклоны зависимостей на обоих адсорбентах выравниваются, 
и уже в случае н-нонана мало различаются. Причем для адсорбента Bsil/CD удлинение углеродного скелета н-алкана на каждую метиленовую группу сопровождается бо́льшим ростом энергии дисперсионного взаимодействия, чем для адсорбента Bsil. Такие различия в поведении линейных углеводородов указывают на разные механизмы адсорбции на двух композиционных адсорбентах.

Различие при адсорбции углеводородов на адсорбентах Bsil и Bsil/CD также прослеживается для соединений, содержащих одинаковое число атомов углерода, но имеющих разное пространственное строение (рисунок 2).

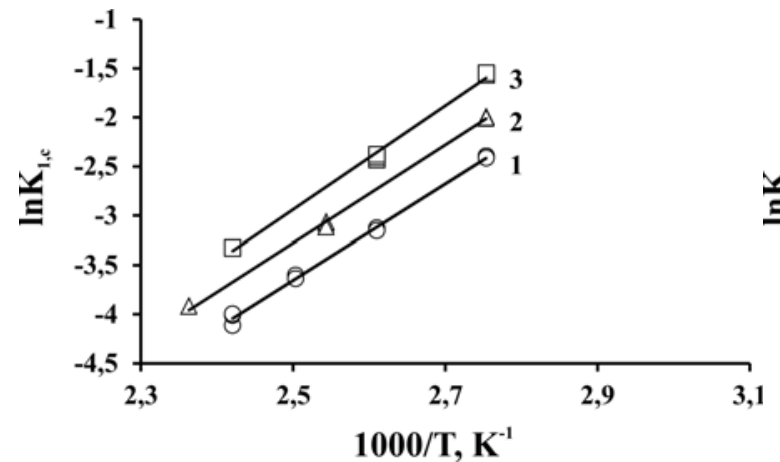

a

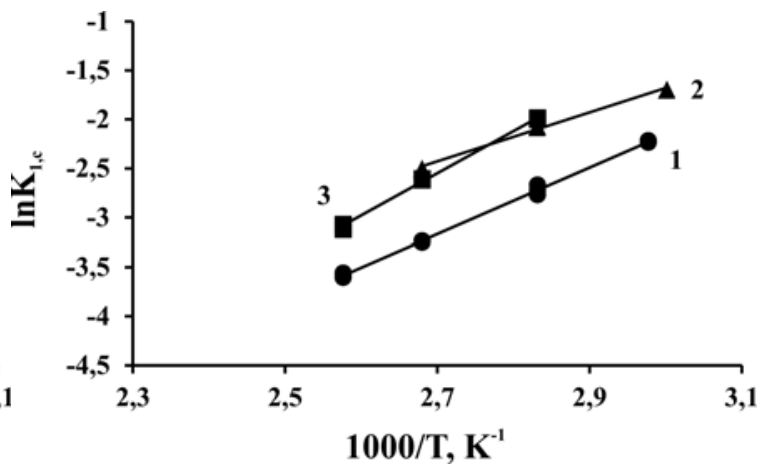

б

Рис. 2. Зависимости логарифма константы Генри от обратной температуры для н-гексана (1), циклогексана (2) и бензола (3) на адсорбентах $\operatorname{Bsil}(a)$ и $\mathrm{Bsil} / \mathrm{CD}(б)$.

В случае адсорбента Bsil для н-гексана, циклогексана и бензола температурные зависимости константы Генри практически параллельны (рисунок $2 a$ ), что указывает на близкие теплоты адсорбции этих соединений. Тогда как для адсорбента Bsil/CD наибольший наклон температурной зависимости отмечается для бензола, а наименьший для циклогексана (рисунок 2б). Это указывает на затрудненность взаимодействия объемных молекул, таких как циклогексан, с макроциклической полостью циклодекстрина.

Для определения возможности образования комплексов включения молекул исследованных адсорбатов с незамещенным $\beta$-циклодекстрином были рассчитаны термодинамические характеристики адсорбции, представленные в таблице 2.

Таблица 2. Термодинамические характеристики адсорбции на адсорбентах Bsil и $\mathrm{Bsil} / \mathrm{CD}$

\begin{tabular}{|c|c|c|c|c|c|}
\hline \multirow[b]{2}{*}{ № } & \multirow[b]{2}{*}{ Адсорбат } & \multicolumn{2}{|c|}{ Bsil } & \multicolumn{2}{|c|}{ Bsil/CD } \\
\hline & & $\begin{array}{c}\bar{q}_{\text {dif }, 1}, \\
\text { кДж/моль }\end{array}$ & $\begin{array}{c}-\Delta \bar{S}_{1, c}^{o}, \\
\text { Дж/(моль } \cdot \text { К })\end{array}$ & $\begin{array}{c}\bar{q}_{d i f, 1} \\
\text { кДж/моль }\end{array}$ & $\begin{array}{c}-\Delta \bar{S}_{1, c}^{o}, \\
\text { Дж/(моль } \cdot \text { К) }\end{array}$ \\
\hline 1 & 2 & 3 & 4 & 5 & 6 \\
\hline 1 & н-Гексан & 40.7 & 140.4 & 28.1 & 110.5 \\
\hline 2 & $h$-Гептан & 45.0 & 145.2 & 31.1 & 112.4 \\
\hline 3 & н-Октан & 49.0 & 149.6 & 41.3 & 133.8 \\
\hline 4 & $\mu$-Нонан & 54.5 & 158.2 & 49.2 & 148.7 \\
\hline 5 & 2,2,4-Триметилпентан & 48.1 & 150.2 & 30.5 & 108.4 \\
\hline 6 & 2,2-Диметилгексан & 47.4 & 147.4 & 34.3 & 117.8 \\
\hline 7 & 2,3-Диметилгексан & 48.4 & 148.4 & 38.0 & 126.6 \\
\hline 8 & 2,3,4-Триметилпентан & 48.1 & 147.1 & 36.2 & 121.6 \\
\hline 9 & Циклогексан & 41.4 & 139.2 & 20.7 & 84.5 \\
\hline 10 & Бензол & 43.9 & 142.4 & 35.7 & 125.8 \\
\hline
\end{tabular}




\begin{tabular}{|c|c|c|c|c|c|}
\hline 1 & 2 & 3 & 4 & 5 & 6 \\
\hline 11 & Толуол & 48.1 & 146.8 & 35.6 & 118.3 \\
\hline 12 & Этилбензол & 57.0 & 163.8 & 38.6 & 120.6 \\
\hline 13 & $o$-Ксилол & 50.6 & 146.9 & 39.5 & 122.2 \\
\hline 14 & м-Ксилол & 49.7 & 146.3 & 41.4 & 127.8 \\
\hline 15 & $n$-Ксилол & 49.6 & 145.9 & 36.8 & 116.2 \\
\hline 16 & Хлорбензол & 50.0 & 147.7 & 33.7 & 110.2 \\
\hline 17 & Пропанол-1 & - & - & 61.0 & 182.8 \\
\hline 18 & Пропанол-2 & - & - & 66.2 & 198.6 \\
\hline 19 & Бутанол-1 & - & - & 58.8 & 168.5 \\
\hline 20 & Метилпропанол-1 & - & - & 62.7 & 182.3 \\
\hline 21 & Метилпропанол-2 & - & - & 67.3 & 200.2 \\
\hline 22 & Пентанол-1 & - & - & 58.2 & 161.3 \\
\hline 23 & 3-Метилбутанол-1 & - & - & 59.9 & 166.1 \\
\hline 24 & (+)-Камфен & \multirow[b]{2}{*}{57.4} & \multirow{2}{*}{158.8} & 38.7 & 118.2 \\
\hline 25 & (-)-Камфен & & & 46.0 & 136.1 \\
\hline 26 & (+)-Лимонен & \multirow{2}{*}{61.7} & \multirow{2}{*}{166.9} & 47.8 & 137.3 \\
\hline 27 & (-)-Лимонен & & & 55.1 & 155.1 \\
\hline 28 & (+)- $\alpha$-Пинен & \multirow{2}{*}{53.0} & \multirow{2}{*}{150.0} & 35.9 & 111.4 \\
\hline 29 & 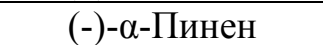 & & & 42.3 & 128.6 \\
\hline
\end{tabular}

Анализ данных таблицы 2 показывает, что наличие циклодекстрина как модификатора привело к снижению термодинамических характеристик адсорбции для всех исследованных соединений. Объясняется это тем, что поверхность наночастиц бутасила покрыта бутильными группами, которые могут занимать до 80 \% поверхности, при этом адсорбирующиеся молекулы взаимодействуют с алкильными группами на поверхности, встраиваясь между ними, что обеспечивает большое число межмолекулярных контактов и высокую степень локализации адсорбатов. В пользу сделанного предположения указывает, например, тот факт, что для н-алканов на адсорбенте Bsil удлинение молекулы на одно метиленовое звено приводит к росту термодинамических характеристик адсорбции в среднем на одну и ту же величину для теплоты адсорбции 5 кДж/моль, для изменения энтропии при адсорбции (по абсолютному значению) 5-7 Дж/(моль КК). В то же время разветвление углеводородного скелета н-алкана не приводит к значимым изменениям термодинамических параметров, что хорошо видно на примере н-октана и его изомеров. Схожая картина наблюдается и для ароматических соединений. Так, при переходе от бензола к толуолу рост термодинамических характеристик адсорбции согласуется с таковым у налканов. Несколько выбивается из этой зависимости этилбензол, что может быть связано с большей доступностью этиленовой группы для межмолекулярных контактов с бутильными группами бутасила. В случае углеводородов с десятью атомами углерода (камфен, лимонен, $\alpha$-пинен) для бициклических каркасных камфена и пинена термодинамические характеристики адсорбции меньше, чем для циклического лимонена, поскольку объемным молекулам тяжелее встраиваться между бутильными фрагментами для реализации максимально возможного количества межмолекулярных контактов.

Поскольку поверхность аэросила не может быть полностью функциализирована алкильными фрагментами, то под ними на поверхности остаются силанольные группы. Их наличие приводит к тому, что спирты адсорбируются крайне сильно за счет образования водородных связей, а их десорбция возможно только при температурах выше $200^{\circ} \mathrm{C}$. По этой причине для них на адсорбенте Bsil в таблице 2 не представлены данные по термодинамическим характеристикам адсорбции. 
В случае адсорбента Bsil/CD циклодекстрин закрывает доступ к бутильным группам и частично включает их в полость, что приводит к изменению характера взаимодействия молекул адсорбатов с адсорбентом. В целом адсорбционный потенциал подложки снижается и компенсируется за счет взаимодействий «макроцикл адсорбат». В отличие от предыдущего адсорбента для Bsil/CD крайне важным фактором при адсорбции становится строение молекул адсорбатов. Например, в ряду ноктана и его изомеров наибольшие термодинамические характеристики адсорбции наблюдаются для первого, что, по-видимому, связано с частичным включением линейной молекулы н-октана в полость и взаимодействием с бутильным фрагментом бутасила. При этом более разветвленным молекулам 2,2,4-триметилпентана и 2,2диметилгексана, имеющим два метильных заместителя при одном атоме углерода в основной цепи, наличие бутильного фрагмента в полости создает стерические затруднения для включения и образования комплекса. Стерические затруднения также возникают при взаимодействии неплоской молекулы циклогексана. При этом, несмотря на то, что линейный размер молекул циклогексана и бензола примерно одинаков (5 $)$, теплота адсорбции последнего на 15 кДж/моль больше, чем у циклоалкана, а величина изменения энтропии на 40 Дж/(моль К). В отличие от адсорбента Bsil у адсорбента $\mathrm{Bsil} / \mathrm{CD}$ удалось получить термодинамические характеристики адсорбции для алканолов. Их анализ указывает на сильные взаимодействия между гидроксильными группами спиртов и циклодекстрина за счет образования водородных связей. Важно отметить, что в отличие от изомеров октана разветвление углеродного скелета в молекуле спирта приводит к усилению межмолекулярных взаимодействий с макроциклом. По-видимому, стерические затруднения в образовании водородных связей у изоспиртов компенсируются возможностью включения в полость циклодекстрина.

Также образование комплексов включения между молекулами адсорбатов и циклодекстрином на адсорбенте Bsil/CD подтверждает наличие у него энантиоселективности. Наибольшая селективность у адсорбента проявилась для изомеров лимонена $\alpha_{-/+}=1.33$ при $\mathrm{t}=90{ }^{\circ} \mathrm{C}$ и камфенов $-\alpha_{-/+}=1.32$ при $\mathrm{t}=90^{\circ} \mathrm{C}$. В случае $\alpha$-пиненов значения фактора разделения несколько меньше, $\alpha_{+/}=1.27$ при $\mathrm{t}=150^{\circ} \mathrm{C}$.

Из анализа полученных данных была предложена возможная структура наночастиц диоксида кремния (бутасила), модифицированных незамещенным $\beta$-циклодекстрином (рисунок 3 ).

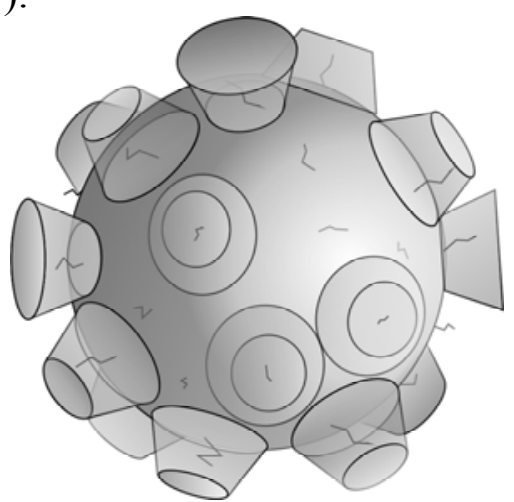

Рис. 3. Предполагаемое строение наночастиц диоксида кремния (бутасила) с циклодекстрином.

В предполагаемой структуре при диаметре частицы 5 нм на ее поверхности может разместиться до 26 молекул циклодекстрина, при этом бутильные фрагменты на поверхности частицы выступают как якорные группы, ориентирующие макроциклические молекулы. 


\section{Заключение}

Таким образом, в работе получены два композиционных адсорбента на основе наночастиц диоксида кремния с привитыми алкильными фрагментами и незамещенного $\beta$-циклодекстрина, охарактеризованы их текстурные и геометрические параметры. Показано, что модифицирование наночастиц бутасила $\beta$-циклодекстрином приводит к незначительному увеличению удельной площади поверхности и порового объема адсорбента Bsil/CD по сравнению с исходным адсорбентом Bsil за счет внутримолекулярных полостей. Установлено, что в случае адсорбента Bsil/CD для молекул изученных адсорбатов обнаруживается комплексообразование по типу «гость - хозяин». Затруднения с включением в полость наблюдаются у циклических и бициклических структур. При этом для алканолов возможно как внешнесферное, так и внутрисферное комплексообразование.

Исследование выполнено при финансовой поддержке РФФИ в рамках научного проекта № 18-33-01302

The reported study was funded by RFBR according to the research project № 18-33-01302

\section{Список литературы}

1. Gupta A., Kumar A., Sharma K.V. et al. // Materials Today: Proceedings. 2018. Vol. 5. pp. 3143-3149.

2. Jintao Liu, Qinghua Li, Shilang Xu // Construction and Building Materials. 2015. Vol. 101. pp. 892-901.

3. Mikhailov M.M., Yuryev S.A., Lovitskiy A.A. // Radiation Physics and Chemistry. 2018. Vol. 151. pp. 266-270.

4. Canfarotta F., Czulak J., Guerreiro A. et al. // Biosensors and Bioelectronics. 2018. Vol. 120. pp. 108-114.

5. Fresco-Cala B., Cárdenas S. // Analytica Chimica Acta. 2018. Vol. 1031. pp. 15-27.

\section{References}

1. Gupta A., Kumar A., Sharma K.V. et al., Materials Today: Proceedings., 2018, Vol. 5, pp. 3143-3149. DOI: 10.1016/j.matpr. 2018.01.121

2. Jintao Liu, Qinghua Li, Shilang Xu, Construction and Building Materials, 2015, Vol. 101, pp. 892-901. DOI: $10.1016 /$ j.conbuildmat. 2015.10.149

3. Mikhailov M.M., Yuryev S.A., Lovitskiy A.A., Radiation Physics and Chemistry, 2018, Vol. 151, pp. 266-270. DOI: 10.1016/ j.radphyschem.2018.06.053

4. Canfarotta F., Czulak J., Guerreiro A. et al., Biosensors and Bioelectronics, 2018, Vol. 120, pp. 108-114. DOI: 10.1016/j.bios. 2018.07.070
6. Przybyszewska M., Krzywania A., Zaborski M. et al. // J. Chromatogr. 2009. Vol. 1216. pp. 5284-5291.

7. Zhou Y., Jin C., Li Y. et al. // Nano Today. 2018. Vol. 20. pp. 101-120.

8. Park C., Youn H., Kim H. et al. // J. Mater. Chem. 2009. Vol. 19. pp. 2310-2315.

9. Abdous B., Sajjadi S.M., Ma'mani L. // J. App. Biomed. 2017. Vol. 15. pp. 210-218.

10.Кудряшов С.Ю., Арутюнов Ю.И., Онучак Л.А. // Журн. физ. химии. 2007. Т. 81. № 1. С. 107-112.

11.Авгуль Н.Н., Киселев А.В., Пошкус Д.П. Адсорбция газов и паров на однородных поверхностях. М. Химия. 1975. 384 с.

5. Fresco-Cala B., Cárdenas S., Analytica Chimica Acta, 2018, Vol. 1031, pp. 15-27. DOI: 10.1016/j.aca.2018.05.069

6. Przybyszewska M., Krzywania A., Zaborski M. et al., J. Chromatogr., 2009, Vol. 1216, pp. 5284-5291. DOI: 10.1016/j.chroma.2009.04.094

7. Zhou Y., Jin C., Li Y. et al., Nano Today., 2018, Vol. 20, pp. 101-120. DOI: 10.1016/j.nantod.2018.04.005 Available at: www.sciencedirect.com.

8. Park C., Youn H., Kim H. et al., J. Mater. Chem., 2009, Vol. 19, pp. 2310-2315. DOI: 10.1039/B816209C 
9. Abdous B., Sajjadi S.M., Ma'mani L., J. App. Biomed., 2017, Vol. 15, pp. 210-218. DOI: 10.1016/j.jab.2017.02.004

10.Kudryashov S.Yu., Arutyunov Yu.I., Onuchak L.A., Russian Journal of Physical Chemi-

Копытина Наталья Александровна - аспирант кафедры физической химии и хроматографии, Самарский национальный исследовательский университет имени академика С.П. Королева, Самара.

Копытин Кирилл Александрович - доцент кафедры физической химии и хроматографии, к.х.н., Самарский национальный исследовательский университет имени академика С.П. Королева, Самара.

Парийчук Михаил Юрьевич - аспирант кафедры физической химии и хроматографии, Самарский национальный исследовательский университет имени академика С.П. Королева, Самара. stry A, 2007, Vol. 81, No 1, pp. 102-107. DOI: 10.1134/S0036024407010190

11.Avgul' N.N., Kiselev A.V., Poshkus D.P., Adsorbcija gazov i parov na odnorodnyh poverhnostjah. M., Khimija, 1975, 384 p.

Kopytina Natalia A. - the postgraduate student, department of physical chemistry and chromatography, Samara University, Samara.

Kopytin Kirill A. - Ph.D. (chemistry), associate prof., department of physical chemistry and chromatography, Samara University, Samara, e-mail: kirko87@inbox.ru

Parijchuk Mihail Yu. - the postgraduate student, department of physical chemistry and chromatography, Samara University, Samara. 